\title{
Distribution of uranium in the internal organs of laboratory animals after incorporation of uranium ore dust
}

\author{
Yelena Saifulina ${ }^{1}$, Sevda Toklayeva $^{1}$, Maxut Sharipov ${ }^{1}$, Riza Medethan ${ }^{1}$, Meirat Bahtin ${ }^{1}$, \\ and Polat Kazymbet ${ }^{1}$
}

${ }^{1}$ JSC Astana medical university/ institute of radiobiology and radiation protection

The aim of the study was to assess the levels of uranium concentration in tissues and organs of laboratory animals by oral ingestion of uranium ore dust into the body.

A series of studies was performed on 43 mature white mongrel rats of both sexes. The animals were divided into two groups: the main group $(n=30)$, where laboratory rats were mixed with uranium ore dust (UOD) at a dose of 50 maximum allowable a concentrations (MAC). Group II $(n=13)$ comprised intact animals. The oral intake of the(UOD) was simulated for 7 days of daily feeding of white outbred rats by the dust of uranium ore mixed with the feed. The dust mass of uranium ore for single feeding of animals of the experimental group at a dose of 50 MPC was $5750 \mathrm{mg}$. Biomaterials were taken after end of oral irradiation 24 hours after the last feeding of UOD. The concentration of uranium in the organs and tissues of rats was measured on an inductively coupled plasma mass spectrometer "Agilent-7800" with a range of measured masses from 2 amu. up to $260 \mathrm{amu}$ Measurements of the specific activity of ${ }^{226} \mathrm{Ra},{ }^{232} \mathrm{Th}$ in rat feces were performed daily after each feeding by spectrometry on a device using the gamma-beta spectrometer Progress-BG.

The content of uranium was measured in the organs of the digestive system: the small intestine and the liver. The average concentration of uranium in the small intestine was 2306.2336.6 ng / 1 and exceeded the corresponding values in the control group by more than 50 times. In the liver, this indicator was also high and 8 times different from the amount of uranium in the control animals - 451.9-315.9 $\mathrm{ng} / 1$. The average uranium content in the kidneys of irradiated rats was 18623.8-4326.4 ng / 1, which significantly differed from the concentration of uranium in the kidneys of intact rats by more than 500 times. In the brain of irradiated rats, the uranium concentration was almost 8 times higher than in the control group and amounted to $17.14 \mathrm{ng} / 1$.

The average value of the specific activity of ${ }^{226} \mathrm{Ra}$ released in feces during the period of admission of UOD into the body of rats was $912.2-460.0 \mathrm{~Bq} / \mathrm{kg}$, with its greatest activity after 2 days of feeding (1420.5-154.9 Bq / kg). In the subsequent week after the termination of internal irradiation, the activity of radium decreased to $211.9 \pm 106.4$, but did not reach the activity values in the control group $(8.3 \mathrm{~Bq} / \mathrm{kg})$. A decrease in the specific activity of ${ }^{232} \mathrm{Th}$ in animal feces did not occur higher values were recorded the following week after feeding $(624.9 \pm 223.1 \mathrm{~Bq} / \mathrm{kg})$ than during the feeding period of OUD $(493.8 \pm 192.9 \mathrm{~Bq} / \mathrm{kg})$.

The results of the experiment demonstrate a faster rate of removal of from ${ }^{226}$ Rathe body of animals through the gastrointestinal tract than ${ }^{232} \mathrm{Th}$. In the early periods after 
internal oral irradiation of UOD animals, the maximum concentrations of uranium are determined in the kidneys, small intestine and liver. 